\title{
Review of case definitions for myalgic encephalomyelitis/chronic fatigue syndrome (ME/CFS)
}

\author{
Eun-Jin Lim and Chang-Gue Son *i)
}

\begin{abstract}
Background: Myalgic encephalomyelitis/chronic fatigue syndrome (ME/CFS) is a debilitating disease with unknown causes. From the perspectives on the etiology and pathophysiology, ME/CFS has been labeled differently, which influenced changes in case definitions and terminologies. This review sought to feature aspects of the history, developments, and differential symptoms in the case definitions.

Methods: A search was conducted through PubMed published to February 2020 using the following search keywords: case definition AND chronic fatigue syndrome [MeSH Terms]. All reference lists of the included studies were checked. Of the included studies, the number of citations and the visibility in the literatures of the definitions were considered for comparisons of the criteria.

Results: Since the first 'ME' case definition was developed in 1986, 25 case definitions/diagnostic criteria were created based on three conceptual factors (etiology, pathophysiology, and exclusionary disorders). These factors can be categorized into four categories (ME, ME/CFS, CFS, and SEID) and broadly characterized according to primary disorder (ME-viral, CFS-unknown, ME/CFS-inflammatory, SEID-multisystemic), compulsory symptoms (ME and ME/ CFS-neuroinflammatory, CFS and SEID-fatigue and/or malaise), and required conditions (ME-infective agent, ME/ CFS, CFS, SEID-symptoms associated with fatigue, e.g., duration of illness). ME and ME/CFS widely cover all symptom categories, while CFS mainly covers neurologic and neurocognitive symptoms. Fatigue, cognitive impairment, PEM, sleep disorder, and orthostatic intolerance were the overlapping symptoms of the 4 categories, which were included as SEID criteria.
\end{abstract}

Conclusions: This study comprehensively described the journey of the development of case definitions and compared the symptom criteria. This review provides broader insights and explanations to understand the complexity of ME/CFS for clinicians and researchers.

Keywords: Myalgic encephalomyelitis, Chronic fatigue syndrome, Systemic exertion intolerance disease, Case definition, Diagnostic criteria

*Correspondence: ckson@dju.ac.kr

Institute of Bioscience and Integrative Medicine, Department of Korean Medicine, Daejeon University, 62 Daehak-ro, Dong-gu, Daejeon, Republic of Korea

\begin{abstract}
Background
Myalgic encephalomyelitis/chronic fatigue syndrome (ME/CFS) is a debilitating disease with core symptoms of fatigue, unrefreshing sleep, postexertional malaise (PEM), and cognitive dysfunction for more than 6 months [1]. This disorder affects individuals of all ages across all socioeconomic, racial, and ethnic groups, 'approximately estimated $1 \%$ of the population, 17 to 24 million people
\end{abstract}


worldwide [2, 3]. The clinical impact of ME/CFS left $27 \%$ of the ME/CFS patients bedridden and 29\% housebound, leading to $50 \%$ unable to work full time and $21 \%$ unable to work at all [4]. In 2015, the Institute of Medicine (IOM) in the U.S. announced that ME/CFS is a serious health problem in the form of complex multisystem neurological disorder, which should be the focus of national medical and scientific effort using the recommended name 'systemic exertion intolerance disorder (SEID)' [5].

Outbreaks of neurological paralysis-related symptoms with systemic malaise have occurred worldwide (e.g., Los Angeles in 1934 and Iceland 1947, followed by New Zealand and Nevada), and ME/CFS was first acknowledged as a form of 'poliomyelitis' and 'benign ME' in the 1930s and 1950s [6-8]. Later, it was known to be sporadic and not rare in the general population [9]. The etiology of the illness has yet to be revealed, which has led to no established objective diagnostics, pathophysiology or therapeutics [4]. Accordingly, many expert groups have developed case definitions based on clinical features. To date, over $20 \mathrm{ME} / \mathrm{CFS}$ case definitions have been established by different groups in various countries [10]. These definitions reflect the historical flow of the clinical features and characteristics of the illness emphasized in a different way according to the perspectives of researchers [11].

Recognition of the changes in the development of the case definitions of ME/CFS is necessary for physicians and researchers to better understand the illness. Differential diagnosis is crucial in the therapeutic process to enhance treatment efficacy; however, a high number of misdiagnoses can lead to delays in the diagnosis and treatment of ME/CFS [12]. Approximately $37 \%$ of ME/ CFS-like patients had experienced alternative diagnoses, such as psychiatric, pain, or sleep disorders, in clinics [13]. Furthermore, the application of particular case definitions profoundly impacts epidemiological studies of ME/CFS [14]. The prevalence of ME/CFS could widely vary based on the application of case definitions; for example, there were fivefold differences in prevalence using the Fukuda $(0.89 \%)$ and the Holmes definition (0.17\%) [15].

Numerous studies have also documented skepticism among physicians about ME/CFS being a distinct clinical entity, and they do not feel confident in making the diagnosis $[12,16]$. One of the reasons is a lack of understanding of ME/CFS, which is likely to result from the complicated backgrounds of this disorder, including indefinite terminologies and etiology. In fact, ME/CFS has been named differently (e.g., postviral fatigue syndrome, neurasthenia) depending on the perspectives of the researchers; likewise, diagnostic criteria or case definitions have also been changed accordingly.
Therefore, this review aims to overview the development of ME/CFS case definitions, which will provide physicians and researchers with a comprehensive picture of the current and prominent features of ME/CFS.

\section{Methods \\ Literature search strategies and data collection}

To comprehensively collect the case definitions of ME/ CFS, we performed a search through PubMed published to February 2020 and checked all reference lists of the included studies. The following search keywords were used: case definition AND chronic fatigue syndrome [MeSH Terms]. We included studies only for adult populations ( $>18$ years), and language was limited to English (Additional file 1. Figure S1).

Two authors independently read all the titles, abstracts, and full text retrieved by the search. The literatures were viewed forward the background of case definitions and analyzed according to time-line based changes. Of those included studies, comparisons of the criteria are limited to the eight definitions (Ramsay, International Consensus Criteria (ICC), Holmes, Australian, Oxford, Fukuda, Canadian Consensus Criteria (CCC), systemic exertion intolerance disease (SEID)) that were selected based on the number of Google Scholar citations and the visibility in the literatures (Additional file 1. Table S1).

\section{Results}

\section{Past and present of ME/CFS}

Since the first recognition of ME/CFS in an outbreak in Los Angeles 1934, the illness has undergone various changes in terminology and case definition [17]. Dr. G. Beard (1839-1883) first disclosed the illness in his book and introduced the term 'neurasthenia' in the $1860 \mathrm{~s} \mathrm{[18].}$ Later, the features of neurologic symptoms during the U.K. outbreaks led to naming the illness 'benign ME' [19], then Ramsay created the 'ME' case definition in 1986 [20]. Serial outbreaks of the illness led to proposing that the condition was linked to viral infection, which altered its name to 'chronic Epstein-Barr virus syndrome (EBVS)' in 1982 [21] and 'postviral fatigue syndrome (PVFS)' in 1985 [22]. In 1988, insufficient evidence in connection with the virus and numerous sporadic cases in the general population led to the Centers for Disease Control and Prevention (CDC) to create the new term 'CFS' (Holmes definition), which was proposed to more inclusively describe the symptom complex, including psychological symptoms [23]. In 2003, the 'ME/CFS' by CCC was published embracing the clinical features of both 'ME' and 'CFS' [24]. The conception of 'ME' or 'ME/CFS' adopted the notion of neuroinflammation [24, 25].

The terminologies of ME, CFS, and/or ME/CFS have been and interchangeably used until present. The 
complexity of those indefinite terminologies is shown in the international code for disease (ICD) system. The WHO initially classified the illness as a neurological disorder in the ICD-8 (code 796.0) in 1969 [26]. Subsequently, the ICD-10 (2016) classified it as PVFS (code G93.3) indexing only 'benign ME' [27] - 'benign' was dropped in the 2019 version [28]. Herein, 'CFS' was not coded; therefore, clinicians instead often used the code of malaise and fatigue (R53), fatigue syndrome (F48) or even neurasthenia (F48) [28, 29]. Meanwhile, the latest version ICD-11 (2019) includes both '(benign) ME' and 'CFS' under PVFS (code 8E49), which noticeably specified exclusion of fatigue (MG22) from the category [30]. This implies that ME/CFS is still loosely defined, yet the perspective of 'CFS' has diverged from 'fatigue', and there was an attempt to view the illness (ME and CFS) as one disorder by using the same ICD code.

In addition, the mischaracterization of the illness in relation to psychological or primarily fatigue-related disorders has contributed to confusion in using the terms. Contrary to the initial 'neurasthenia' that indicated an organic neurological disease, the term was coopted as 'neurosis' that was indicative of psychiatric origin by Dr. S. Freud (1856-1939), who believed the illness was caused by unresolved conflicts in the unconscious mind [31]. Similarly, in the 1970s, McEvedy alleged its psychological origin with the term 'myalgia nervosa' [32]. The debate on the origin of illness (psychological versus neurological) seemed to be controversial until recently [8]. Approximately $20 \%$ of the U.S. media articles during 1987-2013 mislabeled ME/CFS as 'fatigue or psychosomatic-related disorder', which trivialized the illness [33]. Currently, the disorder is generally considered a complex, multisystem neuroimmune disease [34]. In 2015, the IOM suggested a new term SEID and its criteria, thereby reducing the perception derived by the word 'fatigue' and focusing more on the core symptoms that systemically manifest as a physical illness [5].

\section{Outline of the development of the case definitions}

As shown in Fig. 1, to date, 25 case definitions have been developed and published in English. As regards the unique historical backgrounds in the development of these case definitions, we allocated the definitions into

\begin{tabular}{|c|c|}
\hline ME, ME/CFS & CFS, SEID \\
\hline First diagnostic criteria for ME by Ramsay (U.K.) [20] 1986 & \\
\hline London-1990 definition for ME by Dowsett (U.K.) $[60]>1990$ & First definition of CFS by CDC, Holmes (U.S.) [23] \\
\hline Postviral fatigue syndrome, PVFS by Ho-yen Do (U.K.) $[61]>1990$ & Australian definition for CFS by Lloyd (Australia) [62] \\
\hline i & $>$ Oxford definition for CFS by Sharpe (U.K.) [63] \\
\hline I & $>$ NIH definition by Schluederberg (U.S.) [64] \\
\hline London-1994 criteria for ME by Dowsett (U.K.) [65] & CDC 1988 was revised for CFS by Fukuda (U.S.) [35] \\
\hline i & Working case definition for CFS by Komaroff (U.S.) [66] \\
\hline I & $>$ CFS-1998 definition for CFS by Hartz (U.S.) [67] \\
\hline Canadian consensus criteria for ME/CFS & 1 \\
\hline by Carruthers (Canada) $[24]$ & $>$ CDC 2005 empirical definition for CFS by Reeves (U.S.) [36] \\
\hline NICE clinical guidelines for ME/CFS by NIH (U.K.) [68] $<$ & 2007 Empirical-2007 definition for CFS by Jason (U.S.) [69] \\
\hline The Nightingale definition for ME by Hyde (Canada) $[70]<2007$ & Brighton Collaboration definition for CFS by Jones (U.S.) [71] \\
\hline Epidemiological case definition for ME/CFS by Osoba (U.K) $[2]<2007$ & 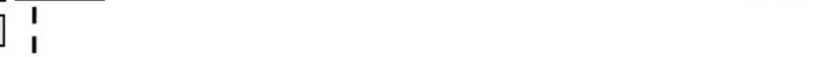 \\
\hline Revised Canadian consensus criteria for ME/CFS $<$ & $\mathbf{I}$ \\
\hline by Jason (U.S.) [37] & I \\
\hline International consensus criteria definition for MF & I \\
\hline $\begin{array}{l}\text { International consensus criteria definition for ME } \\
\qquad \text { by Carruthers (Canada) }[25]<\end{array}$ & i \\
\hline ME-2011 for ME, ME/CFS by Jason (U.S.) [72] $<$ & Maes criteria for ME, CFS, CF by Maes (Thailand) $[40]$ \\
\hline & 2015 IOM diagnostic criteria for SEID by Clayton (U.S.) [5] \\
\hline I & 2015 Maes criteria based on biomarker for CFS by Maes (Australia) [41] \\
\hline $\begin{array}{lllll}2 & 1 \\
\mathbf{1} & \downarrow\end{array}$ & 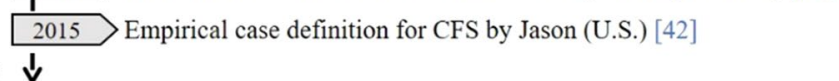 \\
\hline $\begin{array}{l}\text { Fig. } 1 \text { Developmental timeline of ME/CFS case definitions and terminol } \\
\text { CDC Centers for Disease Control and Prevention, NICE National Institute f } \\
\text { exertion intolerance disease. Case definition, a specific set of criteria usec } \\
\text { indicate the presence of an illness (signs and symptoms, test results) }\end{array}$ & $\begin{array}{l}\text { ogies. ME/CFS myalgic encephalomyelitis and chronic fatigue syndrome, } \\
\text { for Health and Clinical Excellence, IOM Institute of Medicine, SEID systemic } \\
\text { d to define a disease for surveillance. Diagnostic criteria, guidance to }\end{array}$ \\
\hline
\end{tabular}


four categories based on characteristics and three by time period.

First, they were divided into ME (mostly published in the U.K.), ME/CFS (mostly Canada), CFS (U.S. and Australia) and SEID (U.S.). The initially distinct view of ME and CFS was later reformulated into ME/CFS and SEID. The feature of these categories is linked to the suggested etiologies: ME by a viral infection, ME/CFS by a neuroinflammatory disorder, CFS with unknown cause, and SEID by multisystemic effects $[5,20,24,35]$. The compulsory symptoms in the ME and ME/CFS criteria stressed neuroinflammation, whereas the symptoms for CFS and SEID focused more on fatigue or malaise [5, 20, 24, 35]. While the ME criteria required the presence of an infective agent, the CFS criteria required the conditions of symptoms associated with fatigue (e.g., duration of the illness).

Second, the definitions can be divided into three groups by the developmental approaches, chronologically: 19861998, 2003-2011, and 2012-2015. By 1998, the ME and CFS definitions were distinctly created and revised based on clinical case reports or committee consensus. In 2003, the merged form of ME/CFS was developed, which first adopted the empirical synthetic strategy using the experiences of physicians and experts [24]. From 2003 to 2011, it was the most evolving period of its development, shifting to empirically derived definitions. For example, CDC-2005 suggested the use of 3 standardized tools, the fatigue-scoring scales; the Medical Outcomes Survey Short Form-36 (SF-36), the Multidimensional Fatigue Inventory (MFI), and the Symptom Inventory (SI) to evaluate symptoms [36]. Additionally, Osoba generated an epidemiological case definition (ECD) based on patient data provided by physicians in 2007 [2]. Similarly, a questionnaire assessing the severity and frequency of the symptoms was adapted to operationalize the key symptoms in development of the revised CCC definition in 2010 [37]. Of interest, in 2011, the CCC extensively changed the definition for ICC-ME, with a greater focus on inflammatory and neurological symptoms [25], however, the lack of evidence of inflammation was problematic [38, 39]. Since 2012, novel strategies using empirical approaches have been recommended, for example, applying statistical analyses of the symptom patterns or comparisons of biomarkers across subgroups of ME/CFS patients [40-42].

Comparison of the symptoms and scope of case definitions As shown in Fig. 2, we selected the eight most prominently cited case definitions and diagnostic criteria (in descending order of the citation: Fukuda, Holmes, Oxford, CCC, ICC, Australian, Ramsay, and SEID) from the 25 case definitions. These definitions can also be categorized into ME (ICC and Ramsay), ME/CFS (CCC), CFS (Holmes, Australian, Oxford, Fukuda), and SEID, according to the focus of primary disorder. 'Cognitive impairment' is the core symptom that commonly intersected in the eight case definitions. In regard to the ME case definitions, the ICC focused on 'physical and cognitive fatigability', while Ramsay particularly emphasized 'muscle fatigability'. Among the CFS definitions, the Australian definition contains the loosest criteria (fatigue, cognitive impairment), in contrast to the Holmes definition that restrictively embraces the other CFS criteria of the Australian, Oxford, Fukuda, and SEID. Those CFS definitions include depression and anxiety in the criteria, unless presented as primary disorder for Fukuda and SEID. The CCC criteria involved both symptom characteristics of ME and CFS, including 'anorexia'. These differences in criteria impact the prevalence rates even in the same population; for example, the rates were $0.19 \%$ with Fukuda, $0.11 \%$ with CCC, and $0.03 \%$ with ECD, among 143,153 participants in the U.K.[14]. Meanwhile, the five symptoms 'fatigue, cognitive impairment, PEM, sleep disorder, and orthostatic intolerance' overlapped with the 4 categories of ME, ME/CFS and CFS, and SEID. In fact, these symptoms are the core signs of SEID [5]. In general, CFS and SEID definitions focused on 'cognitive impairment and fatigue', whereas the ME and ME/CFS further emphasized muscle disturbance with neuro-autonomic symptoms such as sensitivity to food, chemicals or light.

Each case definition generally comprised three categories: required conditions, inclusions and exclusionary symptoms/disorders. Illness $\geq 6$ months, unexplained fatigue, and $\geq 50 \%$ reduced daily activity are commonly required for the CFS, ME/CFS, and SEID definitions, while the ME definitions require the presence of an infective agent (no requirement of 6 months of illness). The above eight definitions have 30 symptoms in the inclusion criteria that can be subcategorized into five groups: 9 neurologic, 6 neurocognitive, 2 neuroendocrine, 5 autonomic, and 7 immunologic symptoms. The ICC, CCC, Holmes, and Fukuda need 4 to 8 symptoms to meet the criteria (Table 1). The ME (Ramsay, ICC) and ME/CFS (CCC) involve all five subcategories, while CFS definitions (Holmes, Australian, Oxford, and Fukuda) cover mainly the neurologic and neurocognitive symptoms. Regarding the exclusionary criteria, CFS, ME/CFS, and SEID definitions recognized depression and anxiety as possible symptoms or comorbidities of the illness, while the ME (Ramsay, ICC) criteria considered those symptoms as exclusions (Table 1). 


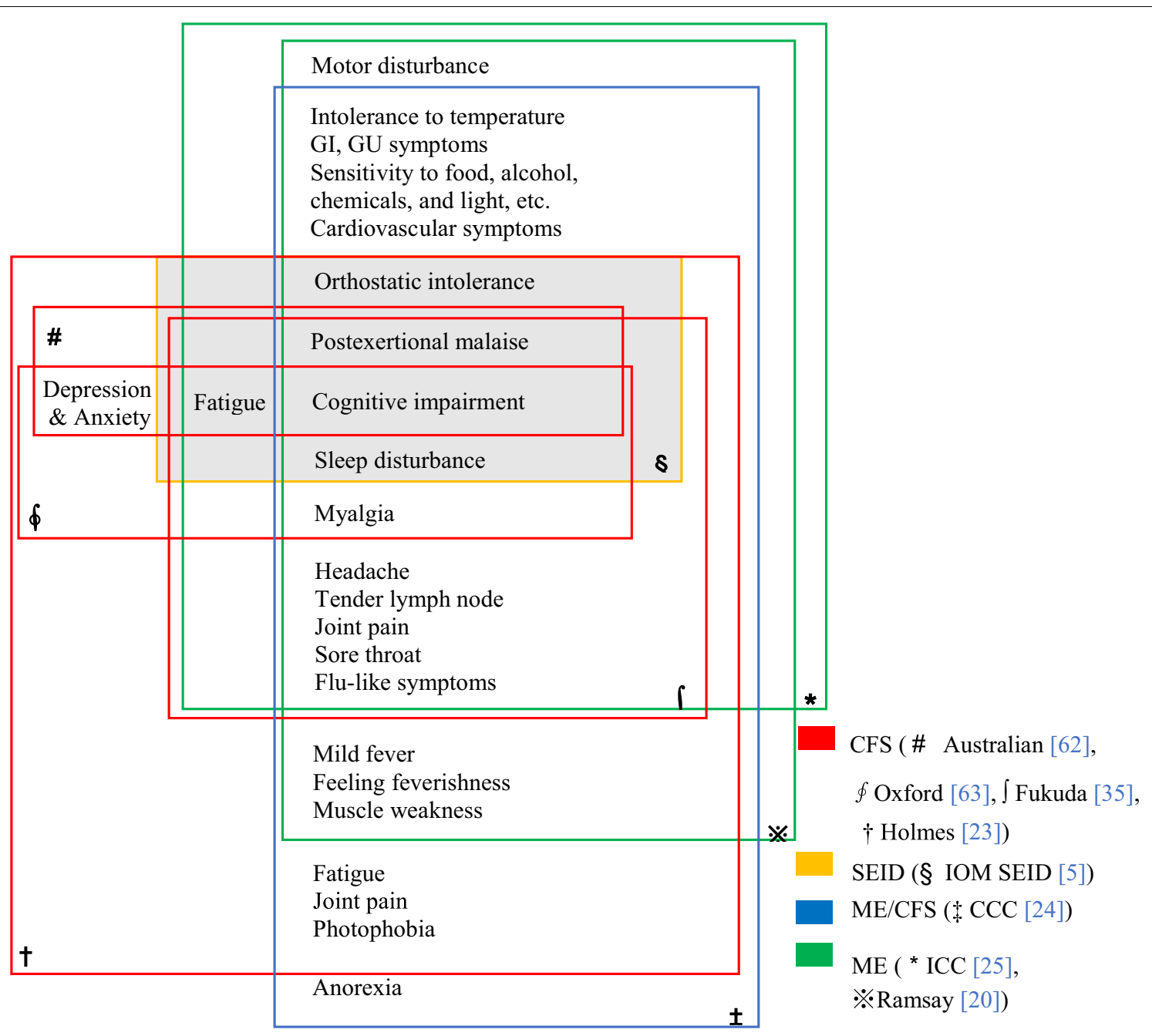

Fig. 2 Scope of ME/CFS symptoms by case definitions. CFS, chronic fatigue syndrome, IOM, Institute of Medicine. SEID, systemic exertion intolerance disorder. ME myalgic encephalitis, CCC Canadian Consensus Criteria, ICC International Consensus Criteria, GI gastro-intestinal, GU genito-urinary symptoms

\section{Discussion and conclusions}

As we described above, the current status of the illness might be linked to the unique historical background of ME/CFS. The decades of effort to unearth this illness is well reflected in the development of case definitions and terminologies. In this review, we found three key factors that have affected ME/CFS case definitions: etiology, pathophysiology, and exclusionary disorders. These factors have impacted the specification of the main symptoms, required conditions, and range of inclusive and exclusive symptoms/disorders in the development of case definitions (Table 2).

Infection, genetics, and environmental factors including trauma, are the most commonly discussed etiologies of ME/CFS, and infection has long been debated as one of the triggers since the initial outbreaks [43]. Some studies have reported the partial linkage between certain viral infections and the development of $\mathrm{ME} /$ CFS [44, 45]; however, the association of virus and this illness has not yet been established. Recently, novel hypotheses have proposed virus-induced alterations in mitochondrial metabolism [46] and autoimmune systems $[47,48]$. These hypotheses are related to some pathophysiologic features involving impairments in the central and autonomic nervous system (CNS and ANS), metabolic function and immunologic system [49]. Recent clinical data support those hypotheses that found widespread neuroinflammation by microglial activation in PET scans [50], lower levels of metabolites [51], and unique patterns of inflammatory cytokines 
Table 1 Comparisons of ME/CFS criteria and symptoms by case definitions

\begin{tabular}{|c|c|c|c|c|c|c|c|c|}
\hline \multirow[t]{2}{*}{ Criteria } & \multicolumn{2}{|l|}{ ME } & \multicolumn{4}{|l|}{ CFS } & \multirow{2}{*}{$\begin{array}{l}\text { ME/CFS } \\
\text { CCC }\end{array}$} & \multirow{2}{*}{$\begin{array}{l}\text { SEID } \\
\text { IOM }\end{array}$} \\
\hline & Ramsay & ICC & Holmes & Australian & Oxford & Fukuda & & \\
\hline \multicolumn{9}{|l|}{ Required conditions } \\
\hline Duration (months) & & & $\geq 6$ & $\geq 6$ & $\geq 6$ & $\geq 6$ & $\geq 6$ & $\geq 6$ \\
\hline New onset (not lifelong) & Infectious & & $\odot$ & & $\odot$ & $\odot$ & $\odot$ & $\odot$ \\
\hline Fatigue (unexplained) & & & - & $\bullet$ & $\bullet$ & - & $\odot$ & $\odot$ \\
\hline Reduced daily activity (\%) & & $\geq 50$ & $\geq 50$ & - & $\geq 50$ & ○ & $\odot$ & $\odot$ \\
\hline Infective agent & ○ & $\bullet$ & & & $\bullet$ & & & \\
\hline N. of symptoms required & & $\begin{array}{l}\geq 8 \\
\geq 1(C / D) \\
\geq 1 \\
\quad(D / E), \geq \mathbf{1} \\
\quad(B / C)\end{array}$ & $\geq 8(1 \geq B)$ & & & $\geq 4$ & $\begin{array}{l}\geq 7 \\
\geq 2 \\
(A / B), \geq 1 \\
(C / D / E)\end{array}$ & $\geq 1$ (B/D) \\
\hline No result of physical exertion & & & & & & $\bullet$ & & 0 \\
\hline No result of mental exertion & & & & & & - & & - \\
\hline No alleviation by rest & & & $\bullet$ & & & $\bullet$ & & $\bullet$ \\
\hline Postexertional malaise ( $\geq 24 \mathrm{~h}$ ) & O & $\bullet$ & $\odot$ & ○ & & $\odot$ & $\bullet$ & - \\
\hline \multicolumn{9}{|l|}{ Inclusions } \\
\hline \multicolumn{9}{|l|}{ A. Neurologic } \\
\hline Myalgia & O & & $\odot$ & & O & $\odot$ & $\odot$ & \\
\hline Muscle weakness & $\bullet$ & $\odot$ & $\odot$ & & & & & \\
\hline Motor disturbance & O & $\odot$ & & & & & & \\
\hline Generalized hyperalgesia & & $\odot$ & & & & & & \\
\hline Joint pain & & $\odot$ & $\odot$ & & & $\odot$ & ○ & \\
\hline New/headaches & ○ & $\odot$ & $\odot$ & & & $\odot$ & ○ & \\
\hline Disturbed sleep patterns & ○ & $\odot$ & $\odot$ & & ○ & & $\odot$ & \\
\hline Unrefreshing sleep & & $\odot$ & & & ○ & $\odot$ & ○ & $\bullet$ \\
\hline Drowsiness & & $\odot$ & & & O & & O & \\
\hline \multicolumn{9}{|l|}{ B. Neurocognitive } \\
\hline Difficulty thinking/processing & & $\odot$ & $\odot$ & ○ & & & $\odot$ & \\
\hline Short-term memory loss & ○ & $\odot$ & $\odot$ & - & O & $\odot$ & $\odot$ & $\odot$ \\
\hline Difficult to focus & ○ & $\odot$ & $\odot$ & O & & $\odot$ & $\odot$ & \\
\hline Depression/anxiety & & & $\odot$ & O & ○ & & & \\
\hline Hypersensitivity to noise/light & O & $\odot$ & $\odot$ & & & & $\odot$ & \\
\hline Tinnitus, double vision & O & & & & & & $\odot$ & \\
\hline \multicolumn{9}{|l|}{ C. Neuroendocrine } \\
\hline Thermostatic instability & O & $\odot$ & & & & & $\odot$ & \\
\hline Anorexia & & & & & & & $\odot$ & \\
\hline \multicolumn{9}{|l|}{ D. Autonomic dysfunction } \\
\hline Orthostatic intolerance & & & & & & & $\odot$ & $\odot$ \\
\hline Cardiovascular & ○ & $\odot$ & & & & & $\odot$ & \\
\hline Respiratory & ○ & $\odot$ & & & & & $\odot$ & \\
\hline Gastro-intestinal (Gl) & $\bigcirc$ & $\odot$ & & & & & $\odot$ & \\
\hline Genito-urinary (GU) & $\bigcirc$ & $\odot$ & & & & & $\odot$ & \\
\hline \multicolumn{9}{|l|}{ E. Immune } \\
\hline Fever or chills & O & & $\odot$ & & & & & \\
\hline Flu-like symptoms & O & $\odot$ & & & & & $\odot$ & \\
\hline Susceptibility to virus & & $\odot$ & & & & & & \\
\hline Sore throat & $\bigcirc$ & & $\odot$ & & & $\odot$ & $\odot$ & \\
\hline Lymph node pain/tenderness & O & & $\odot$ & & & $\odot$ & $\odot$ & \\
\hline Sensitivity to chemicals, foods, medications, odors & & $\odot$ & & & & & $\odot$ & \\
\hline
\end{tabular}


Table 1 (continued)

\begin{tabular}{|c|c|c|c|c|c|c|c|c|}
\hline \multirow[t]{2}{*}{ Criteria } & \multicolumn{2}{|l|}{ ME } & \multicolumn{4}{|l|}{ CFS } & \multirow{2}{*}{$\begin{array}{l}\text { ME/CFS } \\
\text { CCC }\end{array}$} & \multirow{2}{*}{$\begin{array}{l}\text { SEID } \\
\text { IOM }\end{array}$} \\
\hline & Ramsay & ICC & Holmes & Australian & Oxford & Fukuda & & \\
\hline \multicolumn{9}{|l|}{ Exclusions } \\
\hline Medical conditions cause chronic fatigue & $x$ & & $x$ & $x$ & $x$ & $x$ & $x$ & \\
\hline Psychiatric disorders & $x$ & $x$ & $x$ & $x$ & $x$ & $x$ & $x$ & \\
\hline Primary brain disorders & & & $x$ & $x$ & $x$ & $x$ & $x$ & \\
\hline Substance abuse, eating disorder & & $x$ & $x$ & $x$ & $x$ & $x$ & $x$ & \\
\hline Active process of disease & & $x$ & & & & & $x$ & \\
\hline Reactive depression & & $x$ & & & & & & \\
\hline Depression and anxiety & $x$ & & & & & & & \\
\hline
\end{tabular}

CFS chronic fatigue syndrome, ME myalgic encephalitis, CCC Canadian Consensus Criteria, ICC International Consensus Criteria, IOM Institute of Medicine, SEID systemic exertion intolerance disorder

- Compulsory/major symptoms, $\odot$ Optional/minor symptoms, $\bigcirc$ Inclusive symptoms, $x$ Excluded symptoms

Table 2 Summary of classification for the ME/CFS case definitions

\begin{tabular}{|c|c|c|c|c|}
\hline \multirow[t]{2}{*}{ Items } & \multicolumn{4}{|l|}{ Categories } \\
\hline & ME & ME/CFS & CFS & SEID \\
\hline N. of case definitions (Country) & \multicolumn{2}{|l|}{11 (U.K., Canada) } & \multicolumn{2}{|l|}{14 (U.S., Australia) } \\
\hline Author & Ramsay & Carruthers & Holmes & Clayton \\
\hline Publication year & $(1986)$ & $(2003)$ & $(1988)$ & $(2015)$ \\
\hline Most cited eight case definitions & Ramsay, ICC & CCC & Holmes, Australian, Oxford, Fukuda & IOM \\
\hline Primary disorder & Viral & Inflammatory & Unknown & Multisystemic \\
\hline Compulsory symptom & \multicolumn{2}{|c|}{ Neuroinflammatory symptoms (e.g., muscle disturbances) } & \multicolumn{2}{|l|}{ Fatigue and/or malaise } \\
\hline Required conditions & Infective agents & \multicolumn{3}{|c|}{ Symptoms associated with fatigue (e.g., duration of the illness) } \\
\hline Depression and anxiety & Excluded & \multicolumn{3}{|c|}{ Inclusive } \\
\hline Coverage of symptoms & \multicolumn{2}{|c|}{ All five symptom categories* } & \multicolumn{2}{|c|}{$\begin{array}{l}\text { Mainly neurologic and neurocognitive symp- } \\
\text { toms }\end{array}$} \\
\hline $\begin{array}{l}\text { Common symptomof the case } \\
\text { definitions }\end{array}$ & \multicolumn{4}{|l|}{ Cognitive impairment } \\
\hline $\begin{array}{l}\text { Common symptoms of the } \\
\text { categories }\end{array}$ & \multicolumn{4}{|c|}{ Fatigue, cognitive impairment, sleep disorders, orthostatic intolerance } \\
\hline
\end{tabular}

*Five symptom categories: neurologic, neurocognitive, neuroendocrine, autonomic dysfunction, and immune

according to the severity in ME/CFS patients [52]. Additionally, as no single cause has been found, multifactorial contributors (e.g. trauma, toxin exposure, and genetic susceptibility) were suggested [53].

Meanwhile, these various and undefined pathophysiology strongly suggest the possibility of heterogeneous or subsets of ME/CFS [29]. From the empirical analyses of patient symptoms, the neurologic and neurocognitive symptoms were identified as the core symptoms across the major eight definitions [41, 42]. Accordingly, some research groups have tried to classify ME/CFS patients into subgroups for pathophysiologic studies [52, 54, 55]. In fact, a case definition-based diagnosis is problematic, especially for disorders with heterogeneous and unknown underlying pathologies, such as ME/CFS [56]. For the diagnosis of those disorders, the use of diagnostic criteria instead of case definitions are recommended as a more suitable method [56]. Our recent meta-analysis found highly varied prevalence rates of ME/CFS according to the definitions, e.g., rates with Oxford, 1.41\%; Fukuda, 0.89\%; Australian, $0.79 \%$; and Holmes, $0.17 \%$ [15]. This is possibly due to unreliable selection of the homogeneous patient group [10]. The existence of subgroups might lead to continuous changes in the ME/CFS definition, and it may be difficult to differentiate these groups with a diagnosis within a case definition.

Most studies and clinicians adapted those case definitions (instead of diagnostic criteria) since the first case definition in 1988; however, they have been criticized from various aspects. For example, the polythetic 
method (selection 4 out of 8 symptoms) of the Fukuda definition has been claimed to be problematic due to the possibility of misdiagnosis or overdiagnosis of the illness [42]. The Holmes, ICC, and CCC definitions were not exempt from those claims [10]. Hence, in 2015, the IOM announced 'SEID diagnostic criteria' consisting of the diagnostic algorithm based on the core symptoms [5]. Although, SEID has also been criticized for the possibility of increasing prevalence rate [57], SEID criteria seems to be well-matched with the recent findings, such as mild neuro-inflammation and lower levels of metabolites [49-52]. One study found a 2.8 -fold increase in the number of ME/CFS cases with the SEID criteria compared to the Fukuda definition [57].

The perspectives of researchers on etiology and pathophysiology of the illness have influenced on the case definitions, which have been continuously changed. It may be unable to avoid the changes, unless the etiology of ME/CFS is revealed. In this study, we classified the definitions into four concepts and probed the developmental changes in timeline basis. Also, of the compared definitions, it was remarkable that the neurologic and neurocognitive symptom were overlapped among the complex definitions. The possibility of the heterogeneous characteristics of the illness may have critical limitations in case definitions, and then urgently requires the development of objective diagnostic tools for ME/CFS. It is promising that a biological measurement tool using a blood sample-derived nanoelectronics assay could differentiate patients with ME/ CFS from controls [58]. In line with this, to objectively assess PEM, a key symptom of ME/CFS, a standardized technique to measure the level of oxygen uptake using cardiopulmonary exercise testing (CPET) has recently been developed [59]. In addition to the development of advanced diagnostic tools, fine study design or strategies such as the well-constructed patient database, prospective cohort studies and clinical trials for the objective measurement of the core symptoms in particular are needed to comprehensively understand the illness $[1,29,49]$.

In summary, we have comprehensively reviewed the case definitions and the complicated journey in the developments. We herein found the vital differences and similarities among those definitions, particularly the eight definitions that was most likely to be used in research and clinical practice. We didn't intend to seek for a better case definition among them, instead, attempted to shed light on the complexity and confusion of ME/CFS. This review would provide broader insights to understand this complex illness for clinicians and researchers.

\section{Supplementary information}

Supplementary information accompanies this paper at https://doi. org/10.1186/s12967-020-02455-0.

Additional file 1: Table S1 Citations for case definitions of ME/CFS. Figure S1 Flow chart of the study selection process.

\section{Acknowledgements}

Not applicable.

\section{Authors' contributions}

E-JL conducted the literature search, data collection, analysis, and drafted the manuscript. C-GS supported the writing of the manuscript. All authors read and approved the final manuscript.

\section{Funding}

This study was supported by the National Research Foundation of Korea (NRF) funded by the Oriental Medicine R\&D Project (NRF-2018R1A6A1A03025221).

Availability of data and materials

All data related to this study are available in the public domain.

Ethics approval and consent to participate

Not applicable.

Consent for publication

Not applicable.

\section{Competing interests}

There are no potential conflicts of interest to disclose.

Received: 24 April 2020 Accepted: 21 July 2020

Published online: 29 July 2020

References

1. Jason LA, Sunnquist M, Brown A, Evans M, Vernon SD, Furst J, et al. Examining case definition criteria for chronic fatigue syndrome and myalgic encephalomyelitis. Fatigue. 2014;2:40-56.

2. Osoba T, Pheby D, Gray S, Nacul L. The Development of an epidemiological definition for myalgic encephalomyelitis/chronic fatigue syndrome. J Chronic Fatigue Syndr. 2007;14:61-84.

3. American ME and CFS Society. How many people have ME/CFS? U.S. 2019. https://ammes.org/how-many-people-have-mecfs/. Accessed 31 Jan 2019.

4. Bethesda M. Myalgic encephalomyelitis/chronic fatigue syndrome (ME/ CFS) research: workshop report. State of the knowledge workshop. National Institutes of Health. 2011. https://www.meassociation.org.uk/ wp-content/uploads/2011/08/SoK-Workshop-Report-508-compliant-8-511.pdf. Accessed 25 Mar 2019

5. Institute of Medicine. Beyond myalgic encephalomyelitis/chronic fatigue syndrome; Redefining an illness. Institute of medicine of the national academies. 2015. www.nap.edu. Accessed 12 Feb 2019.

6. Parish JG. Early outbreaks of 'epidemic neuromyasthenia'. Postgrad Med J. 1978;54:711-7.

7. Wojcik W, Armstrong D, Kanaan R. Chronic fatigue syndrome: labels, meanings and consequences. J Psychosom Res. 2011;70:500-4.

8. Speight N. Myalgic encephalomyelitis/chronic fatigue syndrome: Review of history, clinical features, and controversies. Saudi J Med Med Sci. 2013:1:11-3.

9. Rowe PC, Underhill RA, Friedman KJ, Gurwitt A, Medow MS, Schwartz MS, et al. Myalgic encephalomyelitis/chronic fatigue syndrome diagnosis and management in young people: a primer. Front Pediatr. 2017;5:121.

10. Brurberg KG, Fonhus MS, Larun L, Flottorp S, Malterud K. Case definitions for chronic fatigue syndrome/myalgic encephalomyelitis (CFS/ME): a systematic review. BMJ open. 2014;4:e003973. 
11. Christley Y, Duffy T, Martin CR. A review of the definitional criteria for chronic fatigue syndrome. J Eval Clin Pract. 2012;18:25-31.

12. Bayliss K, Goodall M, Chisholm A, Fordham B, Chew-Graham C, Riste L, et al. Overcoming the barriers to the diagnosis and management of chronic fatigue syndrome/ME in primary care: a meta synthesis of qualitative studies. BMC Fam Pract. 2014;15:44.

13. Devasahayam A, Lawn T, Murphy M, White PD. Alternative diagnoses to chronic fatigue syndrome in referrals to a specialist service: service evaluation survey. JRSM Short Rep. 2012;3:4.

14. Nacul LC, Lacerda EM, Pheby D, Campion P, Molokhia M, Fayyaz S, et al. Prevalence of myalgic encephalomyelitis/chronic fatigue syndrome (ME/ CFS) in three regions of England: a repeated cross-sectional study in primary care. BMC Med. 2011;9:91.

15. Lim EJ, Ahn YC, Jang ES, Lee SW, Lee SH, Son CG. Systematic review and meta-analysis of the prevalence of chronic fatigue syndrome/myalgic encephalomyelitis (CFS/ME). J Transl Med. 2020;18:100.

16. Bowen J, Pheby D, Charlett A, McNulty C. Chronic Fatigue Syndrome: a survey of GPs' attitudes and knowledge. Fam Pract. 2005;22:389-93.

17. Gilliam AG, National Institutes of Health. Epidemiological study of an epidemic, diagnosed as poliomyelitis, occurring among the personnel of the Los Angeles County General Hospital during the summer of 1934. Washington: US Government Printing Office; 1938.

18. Wessely S. Old wine in new bottles: neurasthenia and 'ME'. Psychol Med. 1990:20:35-533.

19. Jelinek JE. Benign encephalomyelitis. Lancet (London, England). 1956;271:494-5.

20. Ramsay M. Postviral fatigue syndrome: The saga of royal free disease. London: Gower Medical; 1986.

21. Tobi M, Morag A, Ravid Z, Chowers I, Feldman-Weiss V, Michaeli Y, et al. Prolonged atypical illness associated with serological evidence of persistent Epstein-Barr virus infection. Lancet (London, England). 1982;1:61-4.

22. Behan PO, Behan WM, Bell EJ. The postviral fatigue syndrome-an analysis of the findings in 50 cases. J Infect. 1985;10:211-22.

23. Holmes GP, Kaplan JE, Gantz NM, Komaroff AL, Schonberger LB, Straus SE, et al. Chronic fatigue syndrome: a working case definition. Ann Intern Med. 1988;108:387-9.

24. Carruthers BM, Vande SMI. Myalgic Encephalomyelitis/chronic fatigue syndrome: a clinical case definition and guidelines for medical practitioners. An overview of the canadian consensus document. The National Library of Canada. 2003. https://www.investinme.org/Documents/PDFdo cuments/Canadian_ME_Overview_A4.pdf. Accessed 04 Jan 2019.

25. Carruthers BM, van de Sande MI, De Meirleir KL, Klimas NG, Broderick G, Mitchell T, et al. Myalgic encephalomyelitis: International Consensus Criteria. J Intern Med. 2011;270:327-38.

26. World Health Organization. Manual of the international statistical classification of diseases, injuries, and causes of death. International classification of disease. WHO. 1969. https://apps.who.int/iris/handle/10665/70934 . Accessed 03 Mar 2019.

27. World Health Organization. ICD-10. 2016. https://icd.who.int/brows e10/2016/en\#/G90 G99. Accessed 16 Mar 2020.

28. World Health Organization. ICD-10. 2019. https://icd.who.int/brows e10/2019/en\#/G93.3. Accessed 16 Mar 2020.

29. White PD. A perspective on causation of the chronic fatigue syndrome by considering its nosology. J Eval Clin Pract. 2019;25:991-6.

30. World Health Organization. ICD-11 for mortality and morbidity statistics: WHO; 2019. https://icd.who.int/browse11/l-m/en\#/http://id.who.int/icd/ entity/569175314. Accessed 10 Oct 2019.

31. Freud S. The Unconscious. 1915. http://dravni.co.il/wp-content/uploa ds/2014/01/Freud-S.-1915.-The-Unconscious.-.pdf. Accessed 16 Mar 2020.

32. McEvedy CP, Beard AW. A controlled follow-up of cases involved in an epidemic of 'benign myalgic encephalomyelitis'. Brit J Psychiat. 1973;122:141-50

33. Siegel ZA, Brown A, Devendorf A, Collier J, Jason LA. A content analysis of chronic fatigue syndrome and myalgic encephalomyelitis in the news from 1987 to 2013. Chronic IIIn. 2018;14:3-12.

34. Castro-Marrero J, Faro M, Zaragozá MC, Aliste L, de Sevilla TF, Alegre J. Unemployment and work disability in individuals with chronic fatigue syndrome/myalgic encephalomyelitis: a community-based cross-sectional study from Spain. BMC Public Health. 2019;19:840.

35. Fukuda K, Straus SE, Hickie I, Sharpe MC, Dobbins JG, Komaroff A. The chronic fatigue syndrome: a comprehensive approach to its definition and study. International Chronic Fatigue Syndrome Study Group. Ann Intern Med. 1994;121:953-9.

36. Reeves WC, Wagner D, Nisenbaum R, Jones JF, Gurbaxani B, Solomon L, et al. Chronic fatigue syndrome-a clinically empirical approach to its definition and study. BMC Med. 2005;3:19.

37. Jason L, Evans M, Porter N, Brown M, Brown A, Hunnell J, et al. The development of a revised Canadian myalgic encephalomyelitis chronic fatigue syndrome case definition. Am J Biochem Biotechnol. 2010;6:120-35.

38. van der Meer JW, Lloyd AR. A controversial consensus--comment on article by Broderick et al. J Intern Med. 2012;271:29-31.

39. Morris G, Maes M. Case definitions and diagnostic criteria for myalgic encephalomyelitis and chronic fatigue syndrome: from clinicalconsensus to evidence-based case definitions. Neuro Endocrinol Lett. 2013;34:185-99.

40. Maes M, Twisk FN, Johnson C. Myalgic Encephalomyelitis (ME), Chronic Fatigue Syndrome (CFS), and Chronic Fatigue (CF) are distinguished accurately: results of supervised learning techniques applied on clinical and inflammatory data. Psychiatry Res. 2012;200:754-60.

41. Maes M. A new case definition of Neuro-Inflammatory and Oxidative Fatigue (NIOF), a neuroprogressive disorder, formerly known as chronic fatigue syndrome or Myalgic Encephalomyelitis: results of multivariate pattern recognition methods and external validation by neuroimmune biomarkers. Neuro Endocrinol Lett. 2015;36:320-9.

42. Jason LA, Kot B, Sunnquist M, Brown A, Evans M, Jantke R, et al. Chronic fatigue syndrome and myalgic encephalomyelitis: toward an empirical case definition. Health Psychol Behav Med. 2015;3:82-93.

43. Cortes Rivera M, Mastronardi C, Silva-Aldana CT, Arcos-Burgos M. Myalgic encephalomyelitis/chronic fatigue syndrome: a comprehensive review. Diagnostics (Basel). 2019;9(3):91.

44. Holmes GP, Kaplan JE, Stewart JA, Hunt B, Pinsky PF, Schonberger LB. A cluster of patients with a chronic mononucleosis-like syndrome Is Epstein-Barr virus the cause? JAMA. 1987;257:2297-302.

45. Hickie I, Davenport T, Wakefield D, Vollmer-Conna U, Cameron B, Vernon SD, et al. Post-infective and chronic fatigue syndromes precipitated by viral and non-viral pathogens: prospective cohort study. BMJ (Clin Res ed). 2006;333:575.

46. Filler K, Lyon D, Bennett J, McCain N, Elswick R, Lukkahatai N, et al. Association of mitochondrial dysfunction and fatigue: a review of the literature. BBA Clin. 2014;1:12-23.

47. Blomberg J, Gottfries CG, Elfaitouri A, Rizwan M, Rosen A. Infection elicited autoimmunity and myalgic encephalomyelitis/chronic fatigue syndrome: an explanatory model. Front Immunol. 2018;9:229.

48. Sotzny F, Blanco J, Capelli E, Castro-Marrero J, Steiner S, Murovska M, et al. Myalgic encephalomyelitis/chronic fatigue syndrome-Evidence for an autoimmune disease. Autoimmun Rev. 2018:17:601-9.

49. Komaroff AL. Advances in understanding the pathophysiology of chronic fatigue syndrome. JAMA. 2019. https://doi.org/10.1001/ jama.2019.8312.

50. Mueller C, Lin JC, Sheriff S, Maudsley AA, Younger JW. Evidence of widespread metabolite abnormalities in myalgic encephalomyelitis/chronic fatigue syndrome: assessment with whole-brain magnetic resonance spectroscopy. Brain Imaging Behav. 2020;14:562-72.

51. Naviaux RK, Naviaux JC, Li K, Bright AT, Alaynick WA, Wang L, et al. Metabolic features of chronic fatigue syndrome. Proc Natl Acad Sci USA. 2016;113:5472-80.

52. Montoya JG, Holmes TH, Anderson JN, Maecker HT, Rosenberg-Hasson Y, Valencia IJ, et al. Cytokine signature associated with disease severity in chronic fatigue syndrome patients. Proc Natl Acad Sci USA. 2017:114:7150-8

53. Unger ER, Lin JS, Tian H, Gurbaxani BM, Boneva RS, Jones JF. Methods of applying the 1994 case definition of chronic fatigue syndrome-impact on classification and observed illness characteristics. Popul Health Metr. 2016;14:5.

54. Wilson A, Hickie I, Hadzi-Pavlovic D, Wakefield D, Parker G, Straus SE, et al. What is chronic fatigue syndrome? Heterogeneity within an international multicentre study. Aust N Z J Psychiatry. 2001;35:520-7.

55. Collin SM, Nikolaus S, Heron J, Knoop H, White PD, Crawley E. Chronic fatigue syndrome (CFS) symptom-based phenotypes in two clinical cohorts of adult patients in the UK and The Netherlands. J Psychosom Res. 2016;81:14-23. 
56. Coggon D, Martyn C, Palmer KT, Evanoff B. Assessing case definitions in the absence of a diagnostic gold standard. Int J Epidemiol. 2005;34:949-52.

57. Jason LA, Sunnquist M, Kot B, Brown A. Unintended consequences of not specifying exclusionary illnesses for systemic exertion intolerance disease. Diagnostics. 2015;5:272-86.

58. Esfandyarpour R, Kashi A, Nemat-Gorgani M, Wilhelmy J, Davis RW A nanoelectronics-blood-based diagnostic biomarker for myalgic encephalomyelitis/chronic fatigue syndrome (ME/CFS). Proc Natl Acad Sci. 2019;116:10250-7.

59. Stevens S, Snell C, Stevens J, Keller B, VanNess JM. Cardiopulmonary exercise test methodology for assessing exertion intolerance in myalgic encephalomyelitis/chronic fatigue syndrome. Front Pediatr. 2018;6:242.

60. Dowsett EG, Ramsay AM, McCartney RA, Bell EJ. Myalgic encephalomyelitis-a persistent enteroviral infection? Postgrad Med J. 1990;66:526-30.

61. Ho-Yen DO. Patient management of post-viral fatigue syndrome. Br J Gen Pract. 1990;40:37-9.

62. Lloyd AR, Hickie I, Boughton CR, Spencer O, Wakefield D. Prevalence of chronic fatigue syndrome in an Australian population. Med J Aust. 1990;153:522-8.

63. Sharpe MC, Archard LC, Banatvala JE, Borysiewicz LK, Clare AW, David A, et al. A report-chronic fatigue syndrome: guidelines for research. J R Soc Med. 1991;84:118-21.

64. Schluederberg A, Straus SE, Peterson P, Blumenthal S, Komaroff AL, Spring SB, NIH conference, et al. Chronic fatigue syndrome research. Definition and medical outcome assessment. Ann Intern Med. 1992;117:325-31.

65. Dowsett EG, Goudsmit E, Macintyre A, Shepherd CB. London criteria for M.E. Report from the National Task Force on Chronic Fatigue Syndrome (CFS), Post Viral Fatigue Syndrome (PVFS), Myalgic Encephalomyelitis (ME). Westcare. 1994:96-8.
66. Komaroff AL, Fagioli LR, Geiger AM, Doolittle TH, Lee J, Kornish RJ, et al. An examination of the working case definition of chronic fatigue syndrome. Am J Med. 1996;100:56-64.

67. Hartz AJ, Kuhn EM, Levine PH. Characteristics of fatigued persons associated with features of chronic fatigue syndrome. J Chronic Fatigue Syndr. 1998;4:71-977.

68. National Collaborating Centre for Primary Care. NICE clinical guideline 53. Chronic fatigue syndrome/myalgic encephalomyelitis (or encephalopathy): diagnosis and management of cfs/me in adults and children. National Institute for Health and Clinical Excellence. 2007. www.nice.org. uk/guidance/cg53. Accessed 19 Mar 2019.

69. Jason L, Ma K, PhD S. Toward an empirical case definition of CFS. J Soc Serv Res. 2007;34:43-544.

70. Hyde BM. The Nightingale, Myalgic Encephalomyelitis (M.E.) Definition. The Nightingale Research Foundation 2007. https://www.nightingale.ca. Accessed 19 Mar 2019

71. Jones JF, Kohl KS, Ahmadipour N, Bleijenberg G, Buchwald D, Evengard B, et al. Fatigue: case definition and guidelines for collection, analysis, and presentation of immunization safety data. Vaccine. 2007;25:5685-96.

72. Jason LA, Brown A, Clyne E, Bartgis L, Evans M, Brown M. Contrasting case definitions for chronic fatigue syndrome, Myalgic Encephalomyelitis/ chronic fatigue syndrome and myalgic encephalomyelitis. Eval Health Prof. 2012;35:280-304.

\section{Publisher's Note}

Springer Nature remains neutral with regard to jurisdictional claims in published maps and institutional affiliations.
Ready to submit your research? Choose BMC and benefit from:

- fast, convenient online submission

- thorough peer review by experienced researchers in your field

- rapid publication on acceptance

- support for research data, including large and complex data types

- gold Open Access which fosters wider collaboration and increased citations

- maximum visibility for your research: over $100 \mathrm{M}$ website views per year

At BMC, research is always in progress.

Learn more biomedcentral.com/submissions 